\title{
Total Petroleum Hydrocarbon Degradation by Endophytic Fungi from the Ecuadorian Amazon
}

\author{
Fernando Marín 1,2 , Hugo Navarrete ${ }^{2}$, Alexandra Narvaez-Trujillo ${ }^{1,2 *}$ \\ ${ }^{1}$ Center for Research on Health in Latin America (CISeAL), College of Exact and Natural Sciences, PUCE, Quito, Ecuador \\ ${ }^{2}$ School of Biological Sciences, PUCE, Quito, Ecuador \\ Email: *anarvaez@puce.edu.ec
}

How to cite this paper: Marín, F. Navarrete, H. and Narvaez-Trujillo, A. (2018) Total Petroleum Hydrocarbon Degradation by Endophytic Fungi from the Ecuadorian Amazon. Advances in Microbiology, 8, 1029-1053.

https://doi.org/10.4236/aim.2018.812070

Received: November 30, 2018

Accepted: December 26, 2018

Published: December 29, 2018

Copyright (c) 2018 by authors and Scientific Research Publishing Inc. This work is licensed under the Creative Commons Attribution International License (CC BY 4.0)

http://creativecommons.org/licenses/by/4.0/

\begin{abstract}
The capacity of 133 fungal endophyte isolates for degrading petroleum hydrocarbons was evaluated. The endophytes were isolated from leaf and stem tissues from 23 plants collected in a natural habitat contaminated with crude oil in southwestern Ecuador. Their capacity for hydrocarbon biodegradation was tested by an in vitro colorimetric qualitative test during 10 days, using the Minimal Salt Medium and crude oil as the carbon source. Taxonomic identification of the endophytic fungi that showed bioactivity in the qualitative test was carried out by analysis of the ITS gene of the region $18 \mathrm{~S}$ of the rDNA. Endophytes showed the best results in the previous qualitative test where selected for a quantitative in vitro test for 30 days. Residual hydrocarbons were tracked by infrared spectroscopy (IR) and gas chromatography (GC) with a flame ionization detector. The maximum removal rates of total petroleum hydrocarbons were $99.6 \%$ (IR) and $99.8 \%$ (GC), corresponding to fungi of the genus Verticillium sp. and Xylaria sp. 1 respectively. This is the first report of biodegradation of crude oil hydrocarbons by endophytic fungi in a tropical ecosystem. The results suggest these fungal isolates are potential hydrocarbon biodegraders that could be used in bioremediation processes.
\end{abstract}

\section{Keywords}

Fungal Endophyte, Biodegradation, Bioremediation, Hydrocarbon, Infrared Spectroscopy, Gas Chromatography

\section{Introduction}

Petroleum is a non-renewable resource of economic importance for several countries [1], including Ecuador. However, crude oil exploitation is a highly contaminant industry. Water and soil pollution might occur in any stage of production. In a highly biodiverse country, as Ecuador, the impact on habitats 
for local flora and fauna is concerning, in addition to the effects on people's health [2] [3].

Petroleum hydrocarbons (PHs) are categorized into four broad classes of chemical compounds, namely, the aliphatic, aromatic, resin-based, and asphaltene-based hydrocarbons. Each group possesses different physicochemical characteristics and susceptibility to degradation [4] [5].

All hydrocarbon compounds derived from petroleum sources are generally described as total petroleum hydrocarbons (TPHs) and are categorized as aromatic, aliphatic, resin-based and asphaltene-based hydrocarbons. Aliphatic hydrocarbons correspond to linear or cyclic hydrocarbon chains of variable size and structure. It is widely studied for their uses as fuels and solvents. Aromatic hydrocarbons have a variable structure, size and complexity and range from monocyclic structure compounds to compounds formed by long and complex chains, constituted by aromatic rings [6]. Polycyclic aromatic hydrocarbons have been mostly studied, because some of them constitute a wide variety of products of biological, chemical and industrial importance [6]. However, they are also among the pollutants with the greatest biological impact due to their carcinogenic and mutagenic effects [7] [8] [9]. Degradation of these different compounds is highly related to their physical chemical characteristics [10] [11] [12].

Microbial groups, such as bacteria, yeast, and fungi have been identified as principal agents in the degradation of PHs, even though their degradation efficiencies are varying. However, bacteria are the most active and primary degraders of spilled oil in the environment [13]. Remediation techniques have been developed using microorganisms, such as bacteria, yeast and fungi, with varying degradation efficiencies [14]. It is generally suggested that these microorganisms have the metabolic capacity to use hydrocarbons as a carbon source [15]. Also phytoremediation is considered as cost-efficient and eco-friendly and can be implemented after an initial degradation either by bioremediation or physical, chemical and thermal processes.

Bioremediation of petroleum hydrocarbons using native bacterial and fungal isolates from the Ecuadorian soil microbiome has been previously reported [14]. Generally, bioremediation techniques rely on bacteria given their rapid reproduction cycles, their voracity and the facilities for the study of their metabolic pathways [16] [17]. However, recently various studies have reported fungal organisms that exceed bacterial capacities in hydrocarbon biodegradation [18]. Fungi are used due to their particular metabolic capacities, which mediate the transformation of a wide variety of organic compounds to less complex compounds that are later incorporated into their metabolisms [19] [20]; these processes are facilitated due to the characteristics of their complex enzymatic system and their vigorous hyphae growth [15] [19] [21]. Thus, they offer an undeniable potential for their use in bioremediation processes, accordingly, the study of the diversity and identification of species and fungal strains of biotechnological utility should be a priority in an avid field of constant innovation such 
as environmental bioremediation.

In recent years, endophytic fungi have generated major attention in the scientific community due to their wide diversity and particular metabolic capacities [22]. These microorganisms colonize plant tissues, without causing damage or apparent symptoms of disease in their host [13] [23] [24]. They are located in the intercellular spaces and the symplast [25]. Plant and fungi coexist, establishing between them a mutualistic interaction, dependent on the virulence of the fungus and the defenses of the plant. Both elements are influenced by environmental factors and the developmental stage of each organism [24] [26] [27].

Plant-endophyte interaction, be it with bacterial or fungal endophytes, generally improve plant adaptation to the environment by increasing tolerance to biotic and abiotic stress, changes in temperature and salinity, development of resistance to diseases, herbivory, insects, nematodes, bacteria and other pathogenic fungi [28]. The development of resistance to normally lethal or highly hazardous pollutants, such as crude oil, occurs when plants are able to metabolize harmful compounds by extracellular enzymes secreted by endophytic fungi, this process could be developed inside the plant or at soil level by enzymatic secretion through the root [29].

In Ecuador, main oil reservoirs are found in the Cretaceous Hollin and Napo geological formations in the Oriente basin. The Oriente basin, which covers about $100,000 \mathrm{~km}^{2}$, lies between the Andes on the west and the Guyana shield on the east. The basin extends northward into the Putumayo basin in Colombia, and southward into the Maranon basin in Peru [30]. The principal reservoir, the Lower Cretaceous Hollin Formation is characterized by structurally controlled oil accumulations found in the Cretaceous sandstones of this formation. Geochemical analyses indicate that the oil migrated into these structures from Cretaceous source rocks in the eastern Cordillera and southernmost Oriente basin [31]. The oil is trapped in structures of Cretaceous-Oligocene age [32]. On the Hollin-Loreto roadway that connects Ecuador's capital city, Quito, to the Ecuadorian Amazon basin, outcrops can be observed with these oil accumulations. Various plant species have colonized, adapted and proliferated successfully in habitats contaminated with petroleum [33], with this consideration in mind, the vegetation found on the outcrops on the Hollin-Loreto roadway most probably exhibit similar adaptive features.

Therefore, the exploration and identification of the endophytic fungal diversity these plants harbor could lead to the discovery of fungi with metabolic capacities to biodegrade petroleum hydrocarbons by using these as a carbon source, facilitating the adaptation and host plants survival to adverse conditions. These findings could contribute to the innovation and development of new technologies for environmental bioremediation.

This study is primarily aimed to describe plant fungal endophytic diversity of plant communities in a tropical lowland ecosystem exhibiting long term petroleum contamination, as well as to evaluate petroleum hydrocarbon biodegrada- 
tion capacities of the endophytic fungi isolated from plants adapted to crude oil contaminated habitats.

\section{Methods}

\subsection{Sampling Site and Plant Collection}

The collection site is located at the locality "Las Minas" $\mathrm{Km} 10.1$ roadway Hollín-Loreto, Napo Province, Ecuador $\left(0^{\circ} 42^{\prime} 39.63^{\prime \prime} S, 77^{\circ} 44^{\prime} 33.13^{\prime \prime} \mathrm{W}\right)$. The zone is contaminated with crude oil from natural springs. Botanical samples for taxonomic identification were collected from plants growing on oil outcrops. Leaves and stems samples were collected in zip-lock bags from each plant for endophytic fungi isolation.

\subsection{Endophytic Fungi Isolation from Plant Tissues}

Stem samples were surface sterilized and segments of each stem tissue were removed by longitudinal cuts and incubated in Petri dishes with Water Agar (WA) and Potato Dextrose Agar (PDA 1:10), at room temperature [34]. Leaf samples were sterilized, then cut into small quadrangular fragments $\left(0.5 \mathrm{~mm}^{2}\right)$ and incubated in Petri dishes with Malt Extract Agar (MEA 1:10) at room temperature [27]. Each fungus isolated from stem and leaf tissues were transferred to Petri dishes with the 1X PDA by the terminal hyphae method [34], where it remained in culture for seven days.

\subsection{Qualitative Oil Degradation Essays by Endophytic Fungi}

To determine hydrocarbon degradation bioactivity by the endophytic fungal isolates colorimetric tests were carried out on $125 \mathrm{ml}$ Erlenmeyer flasks, with 50 $\mathrm{ml}$ Minimum Salts Medium (MSM) enriched with 1\% crude oil [18] [35] as a carbon source, Tween ${ }^{\circledR} 80$ as surfactant and Dichlorophenol-indophenol (DCFIF) as metabolic activity indicator [18]. Three agar plugs $\left(1 \mathrm{~cm}^{2}\right)$ with individual fungi from axenic cultures of seven days growth were added to the culture medium. This assay was incubated at room temperature, with continuous agitation at $180 \mathrm{rpm}$ during the entire experimental time [18]. The reduction of culture medium, hence usage of petroleum hydrocarbons, were evidenced by gradual color change of the medium over a 10 day period, from deep blue to colorless, these results were tabulated estimating the degree of clarification of the culture media [18]. Additionally, a negative control was carried out using a non-petroleum tolerant fungus. All essays were carried out in triplicate.

\subsection{Quantitative Degradation Essays and Total Petroleum Hydrocarbon Evaluation by Infrared Spectroscopy and Gas Chromatography}

The endophytic fungi that showed the highest levels of clarification in the qualitative essays were selected for these essays. Three endophyte fungus plugs ( 1 $\mathrm{cm}^{2}$ ) from axenic cultures of seven days growth were added to $125 \mathrm{ml}$ Erlen- 
meyer flasks with $50 \mathrm{ml}$ of MSM enriched with $1 \%$ crude oil and Tween ${ }^{\circledR} 80$ [35]. The assay was incubated at room temperature with continuous agitation at 180 rpm during the entire assay. The amount of persistent hydrocarbon in the medium was evaluated after 30 days incubation [35]. Additionally, a negative control without endophyte was carried out. All the essays were carried out in triplicate. To determine hydrocarbon removal rate, residual petroleum oil were extracted from the culture medium and subjected to a Total Petroleum Hydrocarbon (TPH) analysis using infrared (IR) spectroscopy at PUCE's Center for Environmental and Chemical Services (CESAQ-PUCE).

Five endophytes with the best results by IR quantification were selected for evaluation of hydrocarbon degradation capacity by gas chromatography (GC). This new hydrocarbon degradation test was carried out in the same conditions as described [35]. Once the experiment concluded, the mycelium was removed from the liquid phase by filtration. A liquid-liquid ultrasound assisted extraction was performed with the liquid phase, with $6 \mathrm{ml}$ of dichloromethane (DCM) and $5 \mathrm{ml}$ of culture medium, sonicated with a Branson ${ }^{\circledR} 3800$ water bath for three periods of $5 \mathrm{~min}$ each. The organic phase was recovered after the mixture decantation with two additional portions of DCM [36]. The recovered phase was dried with anhydrous sodium sulfate, concentrated with a rotary evaporator and the resulting volume was adjusted to $2 \mathrm{ml}$ with DCM. The final extracts were analyzed by gas chromatography (GC) (Agilent 7890A gas chromatograph), with flame ionization detector (FID), Agilent DB-TPH capillary column $(30 \mathrm{~m} \times 320$ $\mu \mathrm{m} \times 0.25 \mu \mathrm{m})$. The injector and detector temperatures were $250^{\circ} \mathrm{C}$ and $320^{\circ} \mathrm{C}$, respectively. The programmed parameters were $40^{\circ} \mathrm{C}$ for $1 \mathrm{~min}$, a ramp from $40^{\circ} \mathrm{C}$ to $220^{\circ} \mathrm{C}$ with increments of $8^{\circ} \mathrm{C} / \mathrm{min}$. The final temperature of $220^{\circ} \mathrm{C}$ was maintained for $1 \mathrm{~min}$. The control sample was prepared with $2 \mathrm{ml}$ of DCM.

\subsection{Taxonomic Identification of Endophytic Fungi}

The taxonomic identity of the endophytes classified as degraders in the qualitative assays was determined by sequence analysis of the internal transcribed spacer (ITS) region of the $5.8 \mathrm{~S}$ gene of ribosomal DNA (rDNA). Thus, DNA extractions were performed with Chelex ${ }^{\circledR} 100$ in accordance with previously reported procedures [37] [38]. Subsequently, the extracted DNA was amplified using the primers ITS1 (5'-TCCGTAGGTGAACCTGCGG-3') and ITS4 (5'-TCCTCCGCTTATTGATATGC-3') [39]. The Polymerase chain reaction (PCR) was performed in a $50 \mu \mathrm{l}$ mixture containing $10 \mu \mathrm{l}$ of Green GoTaq ${ }^{\circledR}$ Flexi Buffer 1X, $5 \mu \mathrm{l}$ of $\mathrm{MgCl}_{2}(25 \mathrm{mM}), 1 \mu \mathrm{l}$ of dNTPs (10 mM), $2.5 \mu$ of each primer (ITS1 and ITS4) $(30 \mu \mathrm{M}), 5 \eta \mathrm{g} / \mu \mathrm{l}$ of the template, $0.5 \mu \mathrm{l}$ of Taq polymerase (5 units $/ \mu \mathrm{l})$ and $23.5 \mu \mathrm{l}$ of Milli- ${ }^{\circledR}$ autoclaved water. PCR amplifications were performed using the following protocol: $1 \mathrm{~min}$ initial denaturation at $95^{\circ} \mathrm{C} ; 30$ cycles of $1 \mathrm{~min}$ denaturation at $95^{\circ} \mathrm{C}, 30 \mathrm{sec}$ primer annealing at $55^{\circ} \mathrm{C}$ and $1 \mathrm{~min}$ extension at $72^{\circ} \mathrm{C} ; 5 \mathrm{~min}$ extension at $72^{\circ} \mathrm{C}$ and a final holding at $4^{\circ} \mathrm{C}$ [40], the resulting amplicons were sequenced at Macrogen ${ }^{\circledR}$ (Seoul, South Korea). 
For phylogenetic identification of endophytic fungi, the consensus sequences were analyzed by comparing them with other ITS sequences from the National Center for Biotechnology Information (NCBI GenBank ${ }^{\circledR}$ ) database using the Basic Local Alignment Sequence Tool fornucleotide (BLASTn) search. For taxonomic identification, the highest homology sequences obtained by the BLASTn search were used in alignment with the consensus sequences using the bioinformatic software Muscle (Multiple sequence alignment by log-expectation) [41]. Finally, a phylogenetic tree of maximum likelihood was constructed with 130 sequences from the isolated fungi, using the bioinformatic program RAxML (Randomized Axelerated Maximum Likelihood) [42] applying the nucleotide substitution model GTR y (General Time Reversible) and 1000 bootstrap replicates [43]; Spizellomyces punctatus (Chytridiomycota) was used as external group.

\subsection{Statistical Analysis}

A natural-logarithm transformation was used to normalize the TPH (ppm) quantification data distribution, corroborated with a Shapiro-Wilk test ( $\mathrm{p}<$ 0.05). Subsequently, an analysis of variance (ANOVA) was performed with the IR TPH quantification data and a Tukey multiple comparison test was performed $(\mathrm{p}<0.05)$. The data analyses were conducted using the Statistical Package for the Social Sciences software (SPSS, version 22).

\section{Results}

\subsection{Plant Sample Identification}

A total of 23 plants were collected at "Las Minas" sit developing on rocky substrates exhibiting crude oil or on mud (mixture of crude oil, earth and water). The 23 plants were classified in 12 angiosperm families, 1 gymnosperm and 1 bryophyte (Table 1). The botanical samples were taxonomically identified by the Pontificia Universidad Católica del Ecuador Herbarium (HQCA) staff. Among the angiosperms, the families Melastomataceae, Boraginaceae and Poaceae are predominant in the area, reaching together $70 \%$ of the vegetation present, while the rest of vegetation is represented by the families Rubiaceae, Gunneraceae and Urticaceae, among others (Table 1). Two botanical samples were not identified due to the limited material collected; in both cases the plants were unique individuals and exhibited reduced size.

\subsection{Endophytic Fungi Isolation}

A total of 156 endophytic fungi were isolated from stem and leaf samples obtained from the 23 plant specimens collected; these 156 isolates were grouped into 133 morphotypes.

\subsection{Qualitative Oil Degradation Essays by Endophytic Fungi}

The qualitative tests showed several endophytic isolates with crude oil degrading 
Table 1. Taxonomic identification of the collected plants and number of endophytes isolated per plant.

\begin{tabular}{|c|c|c|c|c|}
\hline Plant ID & Family & Genus & Species & $\begin{array}{c}\text { Endophytes } \\
\text { isolated }\end{array}$ \\
\hline FM001 & MELASTOMATACEAE & - & - & 7 \\
\hline FM002 & GLEICHENIACEAE & Gleichenia & sp. & 5 \\
\hline FM003 & MARATTIACEAE & Marattia & sp. & 12 \\
\hline FM004 & POLYPODIACEAE & Polipodium & sp. & 9 \\
\hline FM005 & ORCHIDACEAE & - & - & 2 \\
\hline FM006 & Unidentified & - & - & 10 \\
\hline FM007 & LYCOPODIACEAE & Lycopodium & sp. & 5 \\
\hline FM008 & BORAGINACEAE & - & - & 9 \\
\hline FM009 & MELASTOMATACEAE & Conostegia & sp. & 5 \\
\hline FM010 & CYPERACEAE & Carex & sp. & 2 \\
\hline FM011 & POACEAE & - & - & 6 \\
\hline FM012 & POACEAE & - & - & 2 \\
\hline FM013 & BRYOPHYTA & - & - & 4 \\
\hline FM014 & BORAGINACEAE & - & - & 4 \\
\hline FM015 & MELASTOMATACEAE & Miconia & crassa & 4 \\
\hline FM016 & GUNNERACEAE & - & - & 8 \\
\hline FM017 & Unidentified & - & - & 3 \\
\hline FM018 & EUPHORBIACEAE & Croton & sp. & 9 \\
\hline FM019 & URTICACEAE & Cecropia & maxima & 4 \\
\hline FM020 & POACEAE & - & - & 6 \\
\hline FM021 & BIGNONIACEAE & Jacaranda & sp. & 5 \\
\hline FM022 & RUBIACEAE & - & - & 8 \\
\hline FM023 & POACEAE & - & - & 4 \\
\hline
\end{tabular}

capacities ( $40 \%$ of the isolates) while the remaining fungi none showed any growth in the culture media ( $60 \%$ of the isolates). The parameter evaluated was the culture medium clearance degree, according to visual observation (Figure 1). In these essays, 10 fungi completely cleared the medium before the 10 days established to conclude the test. The remaining fungi showed partial or null changes (Table 2).

\subsection{Quantitative Essays and Total Petroleum Hydrocarbon Determination}

The fungi with the best qualitative assay performance (10 endophytes) were subjected to a test that allows quantification of petroleum hydrocarbons in the culture medium at the beginning and at the end of the essay. Among the fungi with better performance are Clonostachys sp. 2, Aspergillus sp., Verticillium sp., 

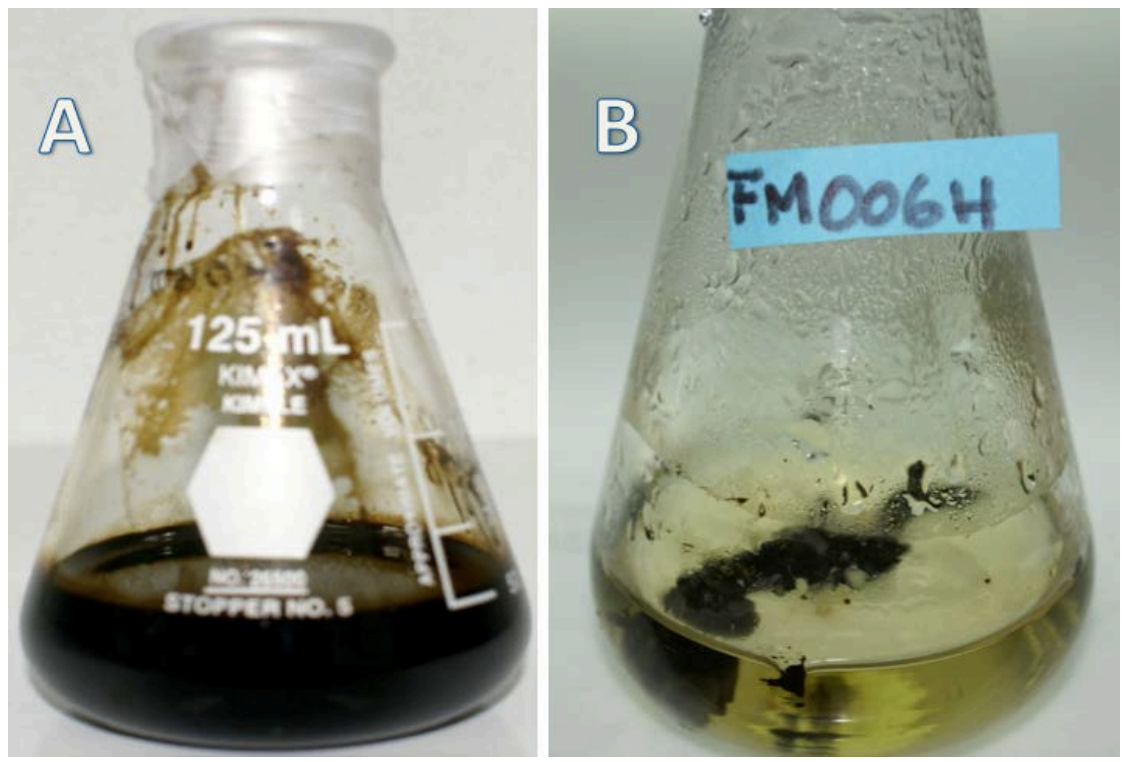

Figure 1. Qualitative test of hydrocarbon biodegradation. (A) Negative control: where the initial appearance of the culture medium product of crude oil is observed (B) Positive result: appearance of the culture medium upon the biodegradation of hydrocarbons by an endophyte fungus, in this case the resulting degradation with Xylaria sp. 8 is observed, observing a total clarification of the culture medium after 10 days of testing.

Table 2. Positive results of endophytic fungi for hydrocarbon qualitative biodegradation essays. Clarification level: mild $(+)$, medium $(++)$, total $(+++)$.

\begin{tabular}{|c|c|c|c|c|}
\hline No. & CEQCA code & Result & Clarification level & Time \\
\hline 1 & CEQCA-N4992 & Positive partial & + & 10 days \\
\hline 2 & CEQCA-N5028 & Positive partial & ++ & 10 days \\
\hline 3 & CEQCA-N5097 & Positive partial & ++ & 10 days \\
\hline 4 & CEQCA-N5096 & Positive & +++ & 7 days \\
\hline 5 & CEQCA-N5011 & Positive & +++ & 5 days \\
\hline 6 & CEQCA-N5012 & Positive & +++ & 8 days \\
\hline 7 & CEQCA-N5071 & Positive & +++ & 5 days \\
\hline 8 & CEQCA-N5005 & Positive partial & + & 10 days \\
\hline 9 & CEQCA-N5090 & Positive partial & + & 10 days \\
\hline 10 & CEQCA-N5091 & Positive partial & ++ & 10 days \\
\hline 11 & CEQCA-N5006 & Positive & +++ & 4 days \\
\hline 12 & CEQCA-N5007 & Positive & +++ & 7 days \\
\hline 13 & CEQCA-N5058 & Positive partial & ++ & 10 days \\
\hline 14 & CEQCA-N5107 & Positive & +++ & 4 days \\
\hline 15 & CEQCA-N5122 & Positive partial & + & 10 days \\
\hline 16 & CEQCA-N5034 & Positive partial & ++ & 10 days \\
\hline 17 & CEQCA-N5035 & Positive partial & + & 10 days \\
\hline 18 & CEQCA-N5036 & Positive partial & + & 10 days \\
\hline
\end{tabular}




\section{Continued}

\begin{tabular}{|c|c|c|c|c|}
\hline 19 & CEQCA-N5037 & Positive partial & ++ & 10 days \\
\hline 20 & CEQCA-N5103 & Positive partial & ++ & 10 days \\
\hline 21 & CEQCA-N5074 & Positive partial & ++ & 10 days \\
\hline 22 & CEQCA-N5033 & Positive partial & + & 10 days \\
\hline 23 & CEQCA-N5102 & Positive & +++ & 6 days \\
\hline 24 & CEQCA-N5087 & Positive partial & + & 10 days \\
\hline 25 & CEQCA-N5088 & Positive partial & ++ & 10 days \\
\hline 26 & CEQCA-N5050 & Positive partial & + & 10 days \\
\hline 27 & CEQCA-N5051 & Positive partial & + & 10 days \\
\hline 28 & CEQCA-N5060 & Positive & +++ & 8 days \\
\hline 29 & CEQCA-N5057 & Positive partial & ++ & 10 days \\
\hline 30 & CEQCA-N5101 & Positive partial & + & 10 days \\
\hline 31 & CEQCA-N5043 & Positive & +++ & 5 days \\
\hline 32 & CEQCA-N5044 & Positive partial & + & 10 days \\
\hline 33 & CEQCA-N5045 & Positive partial & + & 10 days \\
\hline 34 & CEQCA-N5081 & Positive partial & ++ & 10 days \\
\hline 35 & CEQCA-N5076 & Positive partial & ++ & 10 days \\
\hline 36 & CEQCA-N5077 & Positive partial & + & 10 days \\
\hline 37 & CEQCA-N5063 & Positive partial & + & 10 days \\
\hline 38 & CEQCA-N5105 & Positive partial & ++ & 10 days \\
\hline 39 & CEQCA-N5120 & Positive partial & + & 10 days \\
\hline 40 & CEQCA-N5117 & Positive partial & + & 10 days \\
\hline 41 & CEQCA-N5098 & Positive & +++ & 8 days \\
\hline 42 & CEQCA-N5042 & Positive partial & + & 10 days \\
\hline 43 & CEQCA-N5049 & Positive partial & + & 10 days \\
\hline 44 & CEQCA-N5093 & Positive partial & ++ & 10 days \\
\hline 45 & CEQCA-N5094 & Positive partial & ++ & 10 days \\
\hline 46 & CEQCA-N5040 & Positive partial & + & 10 days \\
\hline 47 & CEQCA-N5082 & Positive partial & ++ & 10 days \\
\hline 48 & CEQCA-N5027 & Positive partial & + & 10 days \\
\hline 49 & CEQCA-N5031 & Positive partial & ++ & 10 days \\
\hline 50 & CEQCA-N4995 & Positive partial & + & 10 days \\
\hline 51 & CEQCA-N5021 & Positive partial & ++ & 10 days \\
\hline 52 & CEQCA-N5115 & Positive partial & ++ & 10 days \\
\hline 53 & CEQCA-N5118 & Positive partial & + & 10 days \\
\hline
\end{tabular}

Colletotrichum sp. 1, Phomopsis sp. 1 and Xylaria sp. 1, all of them with a hydrocarbon removal rate average higher than $90 \%$ at the end of the essay. How- 
ever, individuals with lower degrading capacities such as Clonostachys sp. 1, Colletotrichum sp. 2, Colletotrichum sp. 3 and Saccharicola sp. 1, with degradation levels higher than $31 \%$ (Table 3). The TPH results obtained previously by IR quantification were corroborated by a new TPH analysis quantified by GC and carried out only with the fungi that showed the best results (5 endophytes) (Table 3).

The TPH evaluation by GC allowed the identification of aliphatic compounds (octane, nonane, undecane, dodecane and tetradecane) and aromatics (1,2,3-trimethylbenzene, trans-decahydro naphthalene, 1,2,4,5-tetramethylbenzene and pentamethylbenzene) in the control samples. While the culture media where the endophytic fungi were incubated showed that most of the compounds detected in the controls were completely degraded by the fungi Aspergillus sp. and Xylaria sp. 1. The fungi Clonostachys sp. 2, Verticillium sp. and Colletotrichum sp. 1 showed total degradation of the compounds identified in the controls with the exception of n-nonane that showed partial degradation to the controls (14\%, $15 \%$ and $19 \%$ respectively) (Table 4 \& Figure 2 ).

\subsection{Taxonomic Identification of Endophytic Fungi}

A maximum likelihood phylogenetic tree was generated with 53 endophytic fungi that showed hydrocarbon-degrading bioactivity in the qualitative essays, (Figure 3). The phylogenetic analysis showed a total diversity of three phyla, subdivided in 5 classes, 12 orders, 17 families and 14 genera. The majority of fungal isolates belong to the Ascomycota phylum (94.3\%), which represents the dominant lineage. The most abundant class is Sordariomycetes, with $81 \%$ of the isolates. The greatest number of fungal isolates are classified within the Diaporthales and Xylariales orders, $26 \%$ and $22 \%$ of the isolates respectively. Within the Diaporthales

Table 3. Hydrocarbon removal rates quantified by infrared spectroscopy (IR) and gas chromatography (GC).

\begin{tabular}{|c|c|c|c|c|}
\hline \multirow[b]{2}{*}{ Endophyte } & \multicolumn{2}{|c|}{ IR } & \multicolumn{2}{|c|}{ CG } \\
\hline & Removal rate $\%$ & $\begin{array}{l}\text { Standard } \\
\text { deviation }\end{array}$ & Removal rate\% & $\begin{array}{l}\text { Standard } \\
\text { deviation }\end{array}$ \\
\hline Verticillium sp. & 99.64 & 0.21 & 92.41 & 4.55 \\
\hline Xylaria sp. 1 & 98.78 & 0.98 & 99.82 & 0.02 \\
\hline Aspergillus sp. & 97.65 & 0.61 & 99.82 & 0.03 \\
\hline Colletotrichum sp. 1 & 97.46 & 0.02 & 99.75 & 0.01 \\
\hline Clonostachys sp. 2 & 97.41 & 0.94 & 99.69 & 0.01 \\
\hline Phomopsis sp. 1 & 90.67 & 1.76 & - & - \\
\hline Colletotrichum sp. 3 & 86.53 & 0.12 & - & - \\
\hline Saccharicola sp. 1 & 78.94 & 0.26 & - & - \\
\hline Colletotrichum sp. 2 & 70.37 & 2.31 & - & - \\
\hline Clonostachys sp. 1 & 31.46 & 0.01 & - & - \\
\hline
\end{tabular}




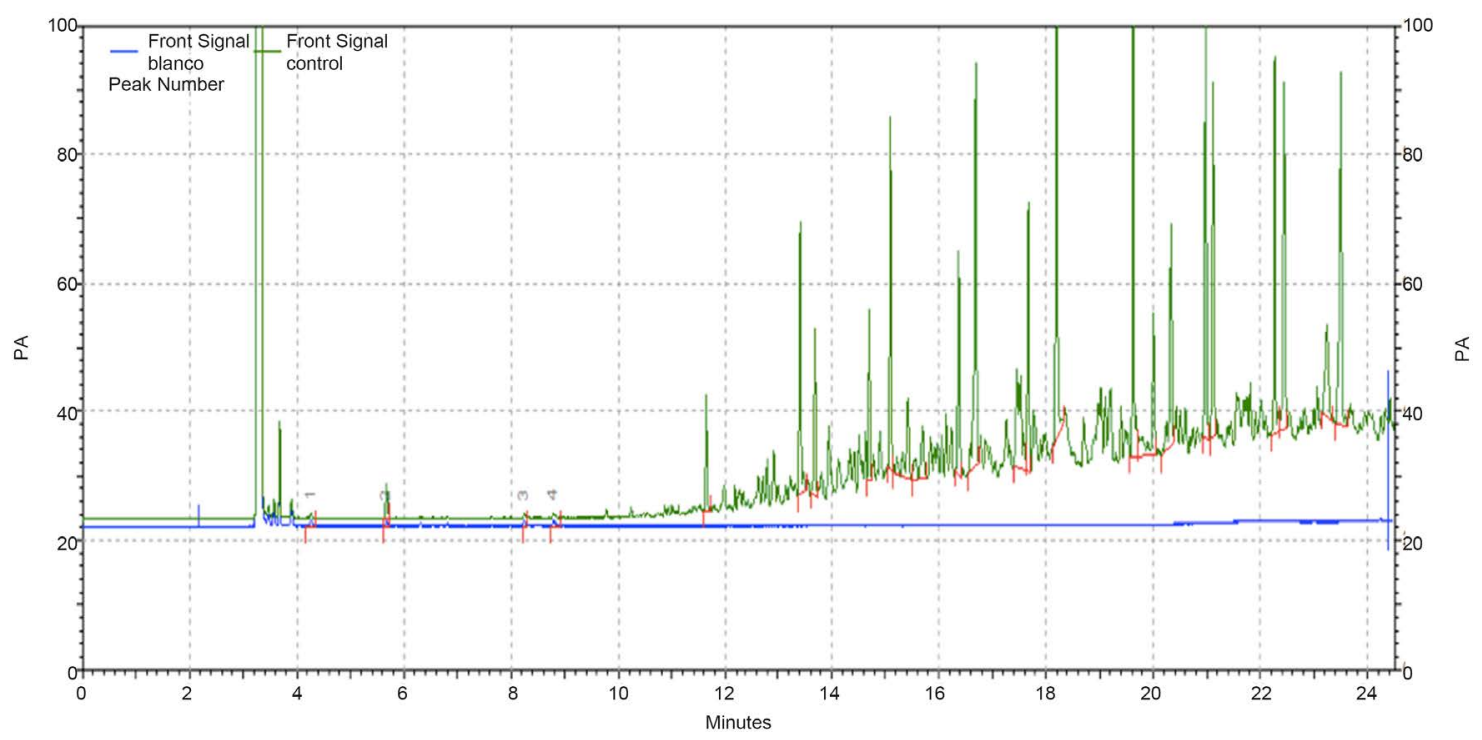

(A)

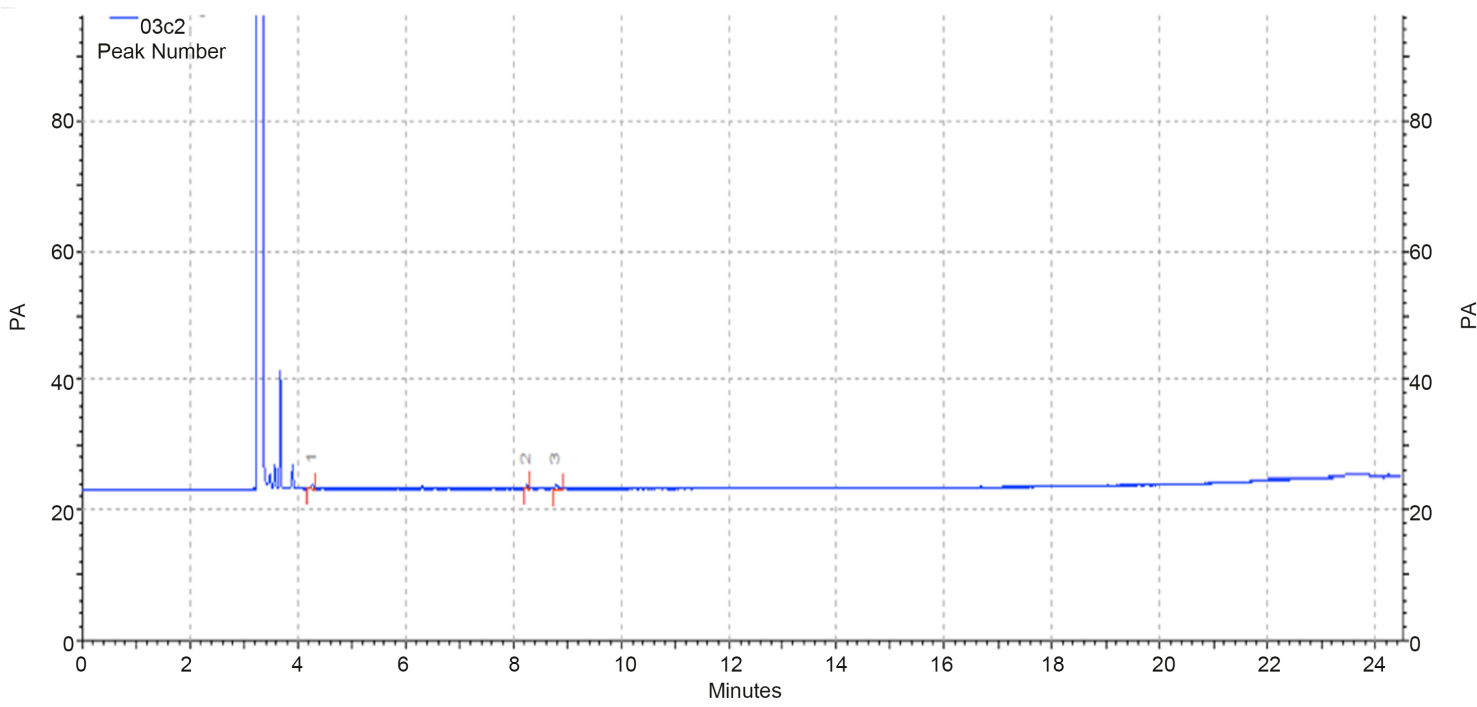

(B)

Figure 2. Chromatograms resulting from the quantification of HTP by gas chromatography (GC) of the quantitative tests. (A) Results of the control sample (green), together with the white DCM sample (blue), in red the peaks with the identified compounds are observed. (B) Results obtained with the endophytic fungus Clonostachys sp. 2.

Table 4. Quantification of persistent petroleum hydrocarbons in the culture medium by gas chromatography (GC) after 30 days of incubation with endophytic fungi.

\begin{tabular}{cccccccc}
\hline \multirow{2}{*}{ Compound } & \multicolumn{2}{c}{ Control } & Verticillium sp. & Clonostachys sp. 2 & Xylaria sp.1 & $\begin{array}{c}\text { Colletotrichum } \\
\text { sp. 1 }\end{array}$ & Aspergillus sp. \\
\cline { 2 - 8 } & $\begin{array}{c}\text { Retention } \\
\text { time }\end{array}$ & Area & Area & Area & Area & Area & Area \\
\hline n-octane & 5.675 & 93,622 & - & - & - & - & - \\
n-nonane & 8.241 & 13,390 & 11,391 & 11,560 & - & 10,450 & - \\
1,2,3-trimetil bencene & 10.242 & 34,895 & - & - & - & - & - \\
Trans-decahidro naftalene & 10.465 & 16,317 & - & - & - & - & - \\
\hline
\end{tabular}




\section{Continued}

\begin{tabular}{cccccc}
\hline 1,2,4,5-Tetrametil bencene & 11.003 & 28,923 & - & - & - \\
n-undecane & 11.517 & 45,834 & - & - & - \\
n-dodecane & 13.482 & 124,133 & - & - & - \\
Pentametil bencene & 15.315 & 204,225 & - & - & - \\
n-tetradecane & 16.868 & 241,542 & - & - & - \\
\hline
\end{tabular}

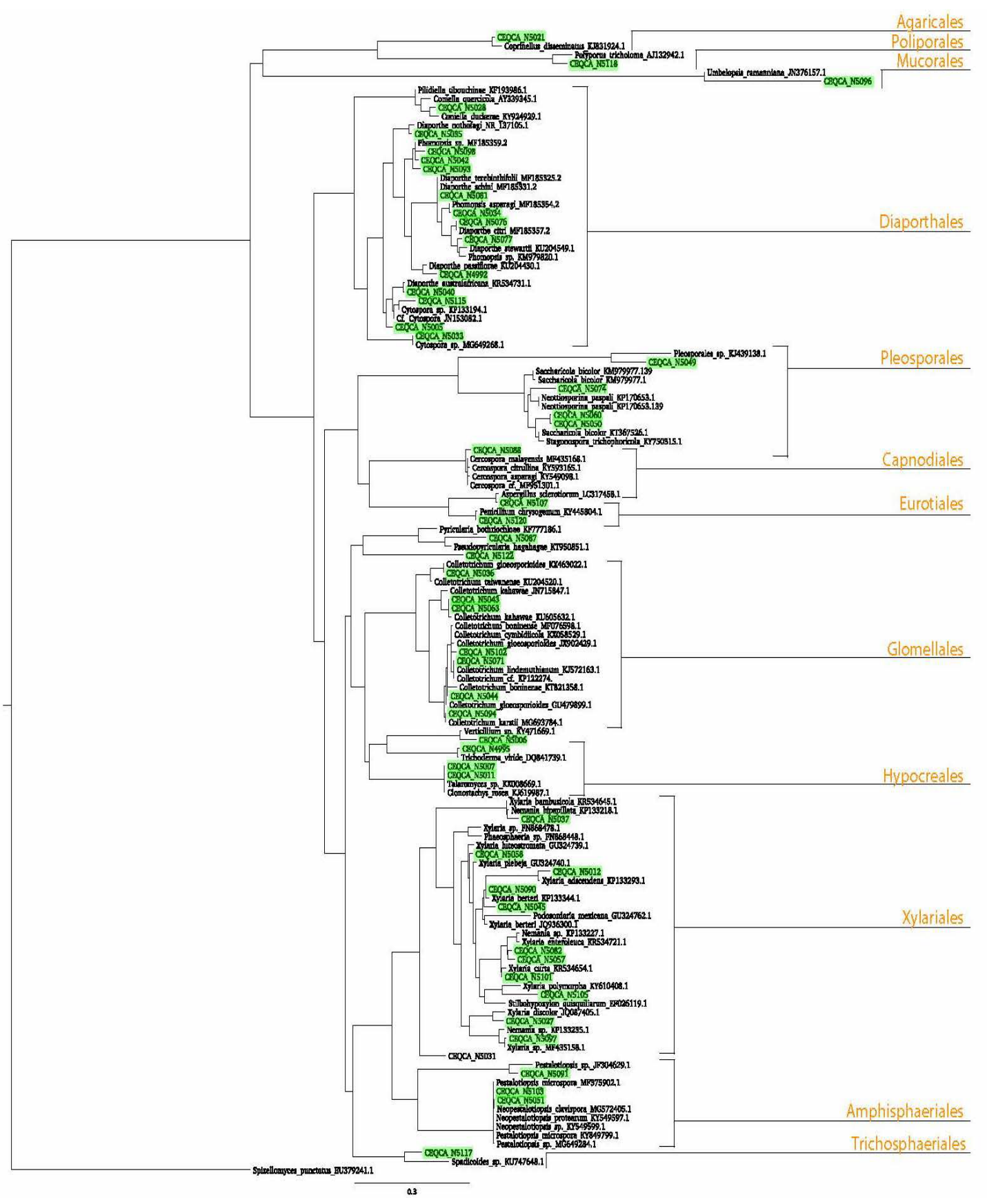

Figure 3. Maximum likelihood phylogenetic tree of the ITS sequences of endophyte hydrocarbon biodegrading fungi. The isolates are shown with the code CEQCA (green), grouped in their respective taxonomic orders (yellow). Spizellomyces punctatus was used as an external group. 
order, the family Diaporthaceae is mostly represented by the genus Diaporthe, with $4.5 \%$ of isolates. Within the Xylariales order, the family Xylariaceae stands out as the only representative, whose members belong to the genus Xylaria. Colletotrichum, genus belonging to the Glomerellaceae family, highlights for being the most represented with $5.3 \%$ of the fungal isolates. Two isolates only could be identified upto order level, one isolate until class level and one at family level. The endophytic fungus Sordariomycetes sp. did not show close homology to any identified specimen at a higher taxonomic level than class. Xylariales sp., Pleosporales sp. and Pyriculariaceae sp. isolates showed a 90\%, 94\% and 91\% BLAST homology level based, respectively (Table 5).

\subsection{Statistical Analysis}

The Shapiro-Wilk test showed a normal distribution of the transformed data, an analysis of variance (ANOVA) was performed, demonstrating the existence of highly significant differences $(\mathrm{p}<0.01)$ between groups (endophytes versus control). The Tukey multiple comparison analysis (Table 6) showed differences between endophytes, constituting homogeneous subgroups based on the degree of variability of the means of each treatment. Three subgroups were established; the first subgroup, comprising the five performing endophytes was selected for an additional trial with CG.

Table 5. Taxonomic identification of 53 hydrocarbon-degrading endophytic fungi isolates. Abreviations: Collection of endophytes Quito-Católica (CEQCA), percentaje of identity (ID), query cover percentaje (QC).

\begin{tabular}{|c|c|c|c|c|c|c|}
\hline No & CEQCA code & ID (\%) & QC (\%) & Genus and species (BLAST) & Established ID & Family \\
\hline 1 & CEQCA-N4992 & 97 & 99 & Diaporthe passiflorae & Diaporthe sp. 5 & Diaporthaceae \\
\hline 2 & CEQCA-N4995 & 99 & 100 & Trichoderma viride & Trichoderma sp. & Hypocreaceae \\
\hline 3 & CEQCA-N5005 & 99 & 100 & Cytospora sp. & Valsaceae sp. 1 & Valsaceae \\
\hline 4 & CEQCA-N5006 & 99 & 100 & Verticillium sp. & Verticillium sp. & Plectosphaerellaceae \\
\hline 5 & CEQCA-N5007 & 100 & 100 & Clonostachys rosea & Clonostachys sp. 1 & Bionectriaceae \\
\hline 6 & CEQCA-N5011 & 100 & 100 & Clonostachys sp. & Clonostachys sp. 2 & Bionectriaceae \\
\hline 7 & CEQCA-N5012 & 99 & 100 & Xylaria adscendens & Xylaria sp. 1 & Xylariaceae \\
\hline 8 & CEQCA-N5021 & 100 & 98 & Coprinellus disseminatus & Coprinellus sp. & Psathyrellaceae \\
\hline 9 & CEQCA-N5027 & 99 & 100 & Xylaria discolor & Xylaria sp.6 & Xylariaceae \\
\hline 10 & CEQCA-N5028 & 98 & 100 & Coniella sp. & Coniella sp. & Schizoparmaceae \\
\hline 11 & CEQCA-N5031 & 90 & 84 & Xylariales sp. & Xylariales sp. & - \\
\hline 12 & CEQCA-N5033 & 100 & 100 & Cytospora sp. & Valsaceae sp. 2 & Valsaceae \\
\hline 13 & CEQCA-N5034 & 99 & 100 & Phomopsis asparagi & Phomopsis sp. 4 & Diaporthaceae \\
\hline 14 & CEQCA-N5035 & 98 & 100 & Diaporthe nothofagi & Diaporthe sp. 4 & Diaporthaceae \\
\hline 15 & CEQCA-N5036 & 100 & 100 & Colletotrichum taiwanense & Colletotrichum sp. 7 & Glomerellaceae \\
\hline 16 & CEQCA-N5037 & 99 & 99 & Xylaria sp. & Xylaria sp.9 & Xylariaceae \\
\hline 17 & CEQCA-N5040 & 99 & 100 & Diaporthe australafricana & Diaporthe sp. 2 & Diaporthaceae \\
\hline
\end{tabular}


Continued

\begin{tabular}{|c|c|c|c|c|c|c|}
\hline 18 & CEQCA-N5042 & 99 & 100 & Phomopsis sp. & Phomopsis sp. 2 & Diaporthaceae \\
\hline 19 & CEQCA-N5043 & 100 & 100 & Colletotrichum kahawae & Colletotrichum sp. 3 & Glomerellaceae \\
\hline 20 & CEQCA-N5044 & 100 & 100 & Colletotrichum sp. & Colletotrichum sp. 6 & Glomerellaceae \\
\hline 21 & CEQCA-N5045 & 99 & 100 & Xylaria sp. & Xylaria sp.10 & Xylariaceae \\
\hline 22 & CEQCA-N5049 & 94 & 100 & Pleosporales sp. & Pleosporales sp. & - \\
\hline 23 & CEQCA-N5050 & 97 & 100 & Saccharicola sp. & Saccharicola sp. 2 & Lophiostomataceae \\
\hline 24 & CEQCA-N5051 & 100 & 99 & Neopestalotiopsis protearum & Pestalotiopsis sp. 2 & Pestalotiopsidaceae \\
\hline 25 & CEQCA-N5057 & 99 & 100 & Nemania sp. & Xylaria sp. 3 & Xylariaceae \\
\hline 26 & CEQCA-N5058 & 99 & 99 & Xylaria plebeja & Xylaria sp. 8 & Xylariaceae \\
\hline 27 & CEQCA-N5060 & 97 & 100 & Saccharicola sp. & Saccharicola sp. 1 & Lophiostomataceae \\
\hline 28 & CEQCA-N5063 & 100 & 100 & Colletotrichum kahawae & Colletotrichum sp. 4 & Glomerellaceae \\
\hline 29 & CEQCA-N5071 & 99 & 100 & Colletotrichum sp. & Colletotrichum sp.1 & Glomerellaceae \\
\hline 30 & CEQCA-N5074 & 97 & 100 & Saccharicola bicolor & Saccharicola sp. 3 & Lophiostomataceae \\
\hline 31 & CEQCA-N5076 & 100 & 100 & Diaporthe citri & Diaporthe sp. 3 & Diaporthaceae \\
\hline 32 & CEQCA-N5077 & 99 & 100 & Diaporthe stewartii & Diaporthe sp. 1 & Diaporthaceae \\
\hline 33 & CEQCA-N5081 & 100 & 100 & Diaporthe sp. & Diaporthe sp. 6 & Diaporthaceae \\
\hline 34 & CEQCA-N5082 & 100 & 99 & Xylaria enteroleuca & Xylaria sp.7 & Xylariaceae \\
\hline 35 & CEQCA-N5087 & 91 & 99 & Pyriculariaceae sp. & Pyriculariaceae sp. & Pyriculariaceae \\
\hline 36 & CEQCA-N5088 & 99 & 100 & Cercospora sp. & Mycosphaerellacae sp. & Mycosphaerellaceae \\
\hline 37 & CEQCA-N5090 & 99 & 100 & Xylaria berteri & Xylaria sp.5 & Xylariaceae \\
\hline 38 & CEQCA-N5091 & 95 & 100 & Pestalotiopsis sp. & Pestalotiopsis sp. 3 & Pestalotiopsidaceae \\
\hline 39 & CEQCA-N5093 & 99 & 99 & Phomopsis sp. & Phomopsis sp. 3 & Diaporthaceae \\
\hline 40 & CEQCA-N5094 & 100 & 100 & Colletotrichum Karstii & Colletotrichum sp. 5 & Glomerellaceae \\
\hline 41 & CEQCA-N5096 & 99 & 100 & Umbelopsis ramanniana & Mucoraceae sp. & Mucoraceae \\
\hline 42 & CEQCA-N5097 & 99 & 100 & Nemania sp. & Xylaria sp.2 & Xylariaceae \\
\hline 43 & CEQCA-N5098 & 100 & 100 & Phomopsis sp. & Phomopsis sp. 1 & Diaporthaceae \\
\hline 44 & CEQCA-N5101 & 100 & 100 & Nemania sp. & Xylaria sp.4 & Xylariaceae \\
\hline 45 & CEQCA-N5102 & 99 & 99 & $\begin{array}{l}\text { Colletotrichum } \\
\text { lindemuthianum }\end{array}$ & Colletotrichum sp. 2 & Glomerellaceae \\
\hline 46 & CEQCA-N5103 & 100 & 99 & $\begin{array}{c}\text { Neopestalotiopsis } \\
\text { clavispora }\end{array}$ & Pestalotiopsis sp. 1 & Pestalotiopsidaceae \\
\hline 47 & CEQCA-N5105 & 89 & 100 & Xylaria sp. & Xylaria sp.11 & Xylariaceae \\
\hline 48 & CEQCA-N5107 & 100 & 100 & Aspergillus esclerotiorum & Aspergillus sp. & Trichocomaceae \\
\hline 49 & CEQCA-N5115 & 99 & 99 & Cytospora sp. & Valsaceae sp. 3 & Valsaceae \\
\hline 50 & CEQCA-N5117 & 92 & 100 & Spadicoides sp. & Helmisthosphaeriaceae sp. & Helminthosphaeriaceae \\
\hline 51 & CEQCA-N5118 & 99 & 98 & Polyporus tricholoma & Polyporus sp. & Polyporaceae \\
\hline 52 & CEQCA-N5120 & 100 & 100 & Penicillium chrysogenum & Penicillium sp. & Trichocomaceae \\
\hline 53 & CEQCA-N5122 & 99 & 100 & Sordariomycetes sp. & Sordariomycetes sp. & - \\
\hline
\end{tabular}


Table 6. Tukey multiple comparisons analysis with the results of the quantification of HTP by infrared spectroscopy.

\begin{tabular}{cccc}
\hline Endophyte & \multicolumn{3}{c}{ Subgroup } \\
\cline { 2 - 4 } & 1.2933 & 2 & 3 \\
\hline Clonostachys sp. 1 & 1.3967 & & \\
Colletotrichum sp. 2 & 2.1933 & 2.1933 & \\
Saccharicola sp. 1 & 2.2200 & 2.2200 & \\
Colletotrichum sp. 3 & 2.2433 & 2.2433 & 2.8033 \\
Phomopsis sp. 1 & & 2.8033 & 2.9667 \\
Clonostachys sp. 2 & & 2.9667 & 3.1633 \\
Colletotrichum sp. 1 & & 3.1633 & 3.3100 \\
Aspergillus sp. & & 3.3100 & 3.6800 \\
Xylaria sp. 1 & & & 3.8433 \\
Verticillium sp. & & & 0.088 \\
Control & 0.152 & 0.054 & \\
Sig. & & & \\
& & & \\
\end{tabular}

\section{Discussion}

Plant adaptation to highly contaminated habitats is restricted to a handful of species that tolerate such conditions [44]. Evidence has shown that endophytes contribute to plant adaptation to stress conditions, stimulating growth, productivity, carbon sequestration and tolerance to contaminants [45].

Deng and Cao [45] suggested that the degree of substrate contamination by hydrocarbons negatively affect plant species diversity and abundance. However, the sampling site of this study exhibits geological oil outcrops with typical Amazonian tropical humid forest vegetation developing in situ, turning this area into a point of interest for the diversity study and capabilities of endophytic fungi from plants adapted to this type of habitat.

The endophytic fungi isolates were subjected to in vitro tests to evaluate their hydrocarbon biodegradation capacity [18]. The qualitative essays showed the hydrocarbon biodegradation potential of 53 endophytic fungi, as indicated in Table 2. The essays are based on the fact that during microorganisms' oxidation reactions, electrons are transferred to an electron acceptor such as oxygen $\left(\mathrm{O}_{2}\right)$, nitrates $\left(\mathrm{NO}_{3}^{-}\right)$or sulfates $\left(\mathrm{SO}_{4}^{2-}\right)$ [46] [47]. By incorporating an electron accepting reagent into the culture medium, such as DCPIP, it is possible to demonstrate the organisms' capacities to use petroleum hydrocarbons as a carbon source through the DCPIP color change, from blue (oxidized) to colorless (reduced) [48]. This redox technique demonstrates that 53 fungal isolates possess the ability to degrade crude oil. Within these 53 endophytes, a subgroup composed of 10 individuals presented outstanding results in the qualitative essays, clarifying completely the culture medium in less time than established for the 
essay ( $<10$ days) (Figure 1$)$.

With exception of plant families Orchidaceae sp. and Poaceae sp., all the collected plants have fungal organisms with variable capacities to degrade hydrocarbons in this essay. Evidence obtained by [49] and [50] demonstrates the plant endophytic composition could be affected by contaminants, stimulating the proliferation of organisms tolerant to these conditions. Interestingly, the plants with the highest number of endophytic isolates, Marattia sp. (Marattiaceae) and FM006 (unidentified), with 12 and 10 isolates respectively, correspond to plants with the highest number of fungi with hydrocarbon biodegradation capacities (Table 2), this results support the hypothesis that endophytes contribute to a better adaptation of the host plant to contaminated substrates [28].

Twenty-three plant samples were collected in the site (Table 1), including stem and leaves samples. The families Melastomataceae, Boraginaceae and Poaceae stood out for their predominance in the area, representing up to $70 \%$ of the species present in the area.

To a lesser degree, individuals from the families Rubiaceae, Gunneraceae and Urticaceae were found. A previous study [33] reported several families in common with this study (Melastomataceae, Boraginaceae, Poaceae, Euphorbiaceae, Bignoniaceae and Rubiaceae) as common species in the tropical Ecuadorian rainforest but evidenced an abnormally higher abundance of them in contaminated secondary forest in contrast to unpolluted secondary forest and pristine forest [33]. In our study the predominant families were Melastomataceae, Rubiaceae, Fabaceae and Euphorbiaceae. The marked predominance of the individuals of the family Melastomataceae could demonstrate a relationship between the family and the colonization of this type of habitat [33]. Likewise, the highest number of fungal endophytes were isolated from plants species of the Melastomataceae, Marattiaceae, Polypodiaceae and Euphorbiaceae which may indicate a strong interaction between the plant and the fungal endophytes, similar to bacteria that are in intimate association with plants which are known to consume alkanes and aromatic hydrocarbon exudates granting them the capacity to in degrade organic contaminants [51].

A total of 133 endophytic fungi were isolated from stem and leaf tissues of 23 plants species (Table 1). These figures are congruent with the suggestion that Ecuadorian endophytes are hyperdiverse [52]. The taxonomic positions of 53 fungi were established through a phylogenetic analysis (Figure 3 ). The phylogenetic tree shows the four phyla in the fungi kingdom, Ascomycota, Basidiomycota, Zygomycota and Spizellomyces punctatus (phylum Chytridiomycota) as outgroup. The analysis shows that most of the isolated ascomycetes constitute the orders Diaporthales, Xylariales and Glomerellales.

Within the order Diaporthales 14 fungi isolates belonging to three families were identified: Diaporthaceae, Valsaceae and Schizoparmaceae. Among the 14 isolates of the order Diaporthales, the endophyte Phomopsis sp. 1 (Table 3) showed a hydrocarbon removal rate of $90.7 \%$. Biodegradation of phenanthrene and 
4-hydroxybenzoic acid has been reported by fungi from the genus Phomopsis [53] [54]; however, this is the first report of crude oil biodegradation for fungi from the genus.

Within the Xylariales order, 12 fungi were identified, 11 belonging to the family Xylariaceae and 1 identified until order level (Table 5). Among the 12 individuals, the endophyte Xylaria sp. 1 showed a hydrocarbons removal rate of 98.8\% (Table 3). Pyrene and benzopyrene biodegradation has been reported by Xylaria regalis [55] but there are no reports to crude oil biodegradation.

The order Glomerellales groups 8 fungi, all belonging to the family Glomerellaceae and the genus Colletotrichum (Table 5). Within this order, three individuals with hydrocarbon removal rates ranging from $70.4 \%$ to $97.5 \%$ (Table 3 ). Colletotrichum gleosporoides is known to produce extracellular lipases [56], enzymes that have been widely studied for their ability to degrade hydrocarbons [57] [58].

However, when submitting Colletotrichum gleosporoides to hydrocarbon biodegradation essay the lipase production capacity was inhibited, possibly due to the impact of the toxic experimental conditions [58].

The order Hypocreales has three identified isolates; the hydrocarbon removal rate to Clonostachys sp. 1 was $31.5 \%$ and $97.4 \%$ to Clonostachys sp. 2 (Table 3). There are no previous reports about hydrocarbon biodegradation by individuals from the genus Clonostachys. But, metabolic capacities studies with individuals from the genus Clonostachys determine zearalenones biodegradation [59].

Aspergillus sp. showed a removal rate of $97.6 \%$ (Table 3). Previous studies conducted with free-living fungi reported the capacities of Aspergillus fumigatus and Penicillium chrysogenum for the production of laccases [58], family of enzymes that are actively involved in the hydrocarbons biodegradation processes by oxidizing them [57] [58]. Additionally, there are biodegradation reports of phenanthrene, pyrene and benzopyrene by Aspergillus niger [60]. Biodegradation of fluoranthene by Penicillium sp., Pyrene by Penicilliumjanczewskii and $P$. janthinellum and crude oil by Penicillium sp. [61] [62]. These works results were obtained with free-living fungi but, belong to the same genus of the endophytes of our study, thus believe the enzymes involved in hydrocarbon biodegradation processes could be the same ones already reported.

The order Pleosporales is represented by four fungi, three belong to the genus Saccharicola, family Lophiostomataceae (Table 5). The endophyte Saccharicola sp. 1 showeda hydrocarbon removal rate of $78.9 \%$ (Table 3). This is the first report of hydrocarbon biodegradation by a fungus from the genus Saccharicola (97\% ID). However, the production of extracellular protease enzymes has been confirmed in individuals of the genus [63], additional studies have identified fungal proteases due to their hydrolytic activity could participate in hydrocarbon degradation processes [57] [58].

Quantification of TPH by IR is based on the measurement of the absorbed energy to produce stretching and bending vibrations of the molecules. The dif- 
ferent functional groups and bond types absorb radiation at different frequencies and intensities. The absorption intensity is directly proportional to the bonds number. This is correlated to the hydrocarbons concentration present in the sample [64]. These results were compared with a control sample to establish the hydrocarbon removal rates.

Previous studies with the same hydrocarbon biodegradation methodology using free-living mushrooms, reported removal rates ranges from $14.9 \%$ to $43.4 \%$ [35]. In this study we obtained variable degradation rates, from $31.5 \%$ (minimum), to $99.6 \%$ (maximum) of hydrocarbon removal, as shown in Table 3.

The analysis also determined a high variation (degradation capacity) among the tested endophytes. The replicates of the trials showed no statistically significant differences.

Additionally, Tukey multiple comparisons analysis grouped the endophytes that showed statistically homogeneous performances among themselves, establishing 3 subgroups, the first subgroup agglutinates the five endophytes with the best performances (Xylaria sp. 1, Clonostachys sp. 2, Colletotrichum sp. 1, Verticillium sp. and Aspergillus sp.) (Table 6). In order to corroborate the results obtained with the best five endophytes, a new analysis was carried out, quantifying the hydrocarbon present in the culture medium by GC. In this TPH quantification method, a mobile phase (inert gas $\mathrm{N}_{2}$ ) and a stationary phase (capillary column) are used to separate the hydrocarbon mixture from the samples in their individual components, carried by the mobile phase through the stationary phase. The separation is carried out by a combination of factors including the boiling point, polarity and affinity differences between the different hydrocarbons and the column, making the concentrations estimation had a greater accuracy and allows establish differences between the quantification methods used.

Removal rates may be affected by several factors, including the test temperature. In the present study, the tests were carried out at a temperature of $23^{\circ} \mathrm{C}$ in absence of an incubator with agitation, but evidence shows that the optimum temperature for carrying out this type of essays ranges between $28^{\circ} \mathrm{C}$ and $31^{\circ} \mathrm{C}$ [65] [66], suggesting the results could be improved modifying the experimental temperature.

Another factor was the addition of a surfactant to the culture medium. There are studies where the culture medium was not supplemented with a surfactant to emulsify the mixture between crude oil and water, making the biodegradation process even more complex for the evaluated microorganisms [67]. In this case, Tween ${ }^{\circledR} 80$, the surfactant used in this study, is nontoxic and a stimulant of manganese peroxidase production [68]; the results obtained indicate that it was the appropriate reagent to optimize the enzymatic activity without toxic effects.

The crude concentration evaluated in this study was $1 \%$; further studies could evaluate the performance of these endophytic fungi at higher concentrations, the optimum concentrations for fungi range between $1 \%$ and $5 \%$ [69]. The crude oil concentration used is determinant to obtain optimal results. Evidence provided 
by [70] shows that the degradation percentage of a bacterial consortium culture decreased from an initial $78 \%$ to $52 \%$ by increasing the crude oil concentration from $1 \%$ to $10 \%$.

The results shown in Table 3 demonstrate the enormous potential of isolated fungi to eventual uses in the bioremediation field. Six fungi (Xylaria sp. 1, Clonostachys sp. 2, Colletotrichum sp. 1, Verticillium sp., Aspergillus sp. and $\mathrm{Mu}$ coraceae sp.) showed removal rates higher than $90 \%$, under the tested conditions, are highly encouraging results for a fungal assay and even more in the case of endophytic fungi.

Reference [50] isolated endophytic bacteria from roots of plants that growing in a contaminated with crude oil environment and evaluated the capacities to biodegrade crude by bacterial isolates at $1 \%$ concentration; obtaining similar hydrocarbon removal rates to those obtained in this study. The isolated Streptomyces sp. HIh9 showed a $97.5 \%$ hydrocarbon removal rate after 7 days of incubation, while in our study the endophyte fungus Verticillium sp. showed 99.64\% after 30 days of incubation, which evidences that plants harbor endophytic contaminant degrading organisms as adaptation mechanism to hostile habitats, due to the plant alone is unable to metabolize these compounds. This study demonstrates the potential for using fungal endophytes in biodegradation of crude oil, either through biotechnological applications or by improving phytoremediation strategies aiding plants to tolerate contaminant-induced stress, especially in countries with economies based on fossil fuel exploitation.

Petroleum hydrocarbon biodegradation is a complex process, depending on the crude oil nature, composition, environmental conditions and soil microbial community. The presence of hydrocarbon-degrading microorganisms is an adaptive response to the environmental contamination conditions [71]. Adaptation mechanisms include selective enrichment and genetic changes that stimulate the complex hydrocarbon biodegradation. The plants forced to develop in this environment stimulate the growth of hydrocarbon-degrading microorganisms to detoxify the plant from substances that normally could not be processed by itself. Fifty-three hydrocarbon-degrading endophytic fungi were isolated from plants growing in crude oil contaminated soils at Ecuadorian Amazon. We identified six endophytic fungi that showed Total Petroleum Hydrocarbon removal rates higher than $90 \%$ after 30 days of incubation. The endophyte Xylaria sp. 1 showed the best TPH removal rate $98.78 \%$ (IR) and $99.8 \%$ (CG).

\section{Conclusion}

Diversity of fungal endophytes determined in this study supports previous reports of hyperdiversity of this group of microorganisms in Ecuador. Our results suggest that bioremediation processes could potentially use hydrocarbon-degrading endophytic fungi isolated from native plant species growing in natural oil outcrops. These may also be used in support of phytoremediation strategies at later stages of remediation of contaminated sites given that the endophytes isolated 
from these plant species may present long-term adaptation mechanisms that can improve colonization of contaminated habitats, as well as uptake by plant species.

\section{Acknowledgements}

The authors wish to acknowledge financial support of this research by the Pontifical Catholic University of Ecuador. Plant and endophyte collections were carried out through the Ecuadorian Ministry of the Environment permit 001-14 IC-MC-DBN/MA. We thank Elisa Jara, School of Chemical Sciences at PUCE and the Center of Environmental and Chemical Services of the PUCE (CESAQ-PUCE) for assistance in the evaluation of hydrocarbon biodegradation. Special thanks to Carolina Portero for technical assistance and Javier Carvajal for valuable comments.

\section{Conflicts of Interest}

The authors declare no conflicts of interest regarding the publication of this paper.

\section{References}

[1] Fontaine, G. (2013) Sobre Bonanzas y Dependencia: Petróleo y Enfermedad Holandesa en el Ecuador. Íconos-Revista de Ciencias Sociales,13, 102-110. https://doi.org/10.17141/iconos.13.2002.628

[2] San Sebastian, M. and Hurtig, A. (2004). Oil Exploitation in the Amazon Basin of Ecuador: A Public Health Emergency. Pan American Journal of Public Health, 15, 109-116. https://doi.org/10.1590/S1020-49892004000300014

[3] Jadoon, S., Amin, A.A., Malik, A. and Khalel, H. (2016) Effects of Crude Oil Contamination under the Controlled Conditions on the Physicochemical Properties of Water in Khurmala and Guwayar, Kurdistan Region, Iraq. Journal of Pollution Effeccts and Control, 4, 2.

[4] Mishra, S., Jyot, J., Kuhad, R.C. and Lal, B. (2001) Evaluation of Inoculum Addition to Stimulate in Situ Bioremediation of Oily-Sludge-Contaminated Soil. Applied and Environmental Microbiology, 67, 1675-1681. https://doi.org/10.1128/AEM.67.4.1675-1681.2001

[5] Sugiura, K., Ishihara, M., Shimauchi, T. and Harayama, S. (1996) Physicochemical Properties and Biodegradability of Crude Oil. Environmental Science \& Technolo$g y$, 31, 45-51. https://doi.org/10.1021/es950961r

[6] Tisot, B. and Welte, D. (2013) Biological Productivity of Modern Aquatic Environments. Springer Science \& Business Media, New York.

[7] Peltonen, K. and Kuljukka, T. (1995) Air Sampling and Analysis of Polycyclic Aromatic Hydrocarbons. Journal of Chromatography, 710, 93-108. https://doi.org/10.1016/0021-9673(95)00207-4

[8] Hurtig, A.K. and San Sebastián, M. (2002) Geographical Differences in Cancer Incidence in the Amazon Basin of Ecuador in Relation to Residence near Oil Fields. International Journal of Epidemiology, 31, 1021-1027. https://doi.org/10.1093/ije/31.5.1021

[9] Cuadras, A., Ramírez, N., Rovira, E., Marcé, R. and Borrull, F. (2012) Evaluación del 
Riesgo Asociado a la Exposición de Hidrocarburos Aromáticos Policíclicos en la Salud de la Población Residente Alrededor del Complejo Químico de Tarragona. Revista de Salud Ambiental, 12, 14-25.

[10] Raju, M.N. and Scalvenzi, L. (2018) Petroleum Degradation: Promising Biotechnological Tools for Bioremediation. In Recent Insights in Petroleum Science and Engineering. InTech. https://doi.org/10.5772/intechopen.70109

[11] Mishra, S., Jyot, J., Kuhad, R.C. and Lal, B. (2001) Evaluation of Inoculum Addition to Stimulate in Situ Bioremediation of Oily-Sludge-Contaminated Soil. Applied and Environmental Microbiology, 67, 1675-1681. https://doi.org/10.1128/AEM.67.4.1675-1681.2001

[12] Sugiura, K., Ishihara, M., Shimauchi, T. and Harayama, S. (1996) Physicochemical Properties and Biodegradability of Crude Oil. Environmental Science \& Technolo$g y$, 31, 45-51. https://doi.org/10.1021/es950961r

[13] Khan, R., Shahzad, S. and Choudhary, M. (2010) Communities of Endophytic Fungi in Medicinal Plant Withania somnifera. Pakistan Journal of Botany, 42, 1281-1287.

[14] Maddela, N.R., Scalvenzi, L. and Venkateswarlu, K. (2017) Microbial Degradation of Total Petroleum Hydrocarbons in Crude Oil: A Field-Scale Study at the Low-Land Rainforest of Ecuador. Environmental Technology, 38, 2543-2550. https://doi.org/10.1080/09593330.2016.1270356

[15] Hammel, K.E. (1995) Mechanisms for Polycyclic Aromatic Hydrocarbons. Degradation by Ligninolytic Fungi. Environmental Health Perspectives, 103, 41.

[16] Pieper, D.H. and Reineke, W. (2000) Engineering Bacteria for Bioremediation. Current Opinion in Biotechnology, 11, 262-270. https://doi.org/10.1016/S0958-1669(00)00094-X

[17] Reda, A.B. (2009) Bacterial Bioremediation of Polycyclic Aromatic Hydrocarbons in Heavy Oil Contaminated Soil. Journal of Applied Sciences Research, 5, 197-201.

[18] Al-Nasrawi, H. (2012) Biodegradation of Crude Oil by Fungi Isolated from Gulf of Mexico. Journal of Bioremediation and Biodegradation, 3, 147.

[19] Cerniglia, C.E. (1997) Fungal Metabolism of Polycyclic Aromatic Hydrocarbons: Past, Present and Future Applications in Bioremediation. Journal of Industrial Microbiology \& Biotechnology, 19, 324-333. https://doi.org/10.1038/sj.jim.2900459

[20] Pointing, S. (2001) Feasibility of Bioremediation by White-Rot Fungi. Applied Microbiology and Biotechnology, 57, 20-33. https://doi.org/10.1007/s002530100745

[21] Drevinskas, T., Mickienè, R., Maruška, A., Stankevičius, M., Tiso, N., Mikašauskaitė, J. and Stankevičienè, A. (2016) Downscaling the in Vitro Test of Fungal Bioremediation of Polycyclic Aromatic Hydrocarbons: Methodological Approach. Analytical and Bioanalytical Chemistry, 408, 1043-1053. https://doi.org/10.1007/s00216-015-9191-3

[22] Schulz, B., Boyle, C., Draeger, S., Römmert, A.K. and Krohn, K. (2002) Endophytic Fungi: A Source of Novel Biologically Active Secondary Metabolites. Mycological Research, 106, 996-1004. https://doi.org/10.1017/S0953756202006342

[23] Arnold, E.A. (2007) Understanding the Diversity of Foliar Endophytic Fungi: Progress, Challenges, and Frontiers. Fungal Biology Reviews, 21, 51-66. https://doi.org/10.1016/j.fbr.2007.05.003

[24] Kusari, S., Hertweck, C. and Spiteller, M. (2012) Chemical Ecology of Endophytic Fungi: Origins of Secondary Metabolites. Chemistry \& Biology, 19, 792-798. https://doi.org/10.1016/j.chembiol.2012.06.004

[25] Strobel, G.A. and Daisy, B. (2003) Bioprospecting for Microbial Endophytes and 
Their Natural Products. Microbiology and Molecular Biology Reviews, 67, 491-502. https://doi.org/10.1128/MMBR.67.4.491-502.2003

[26] Schulz, B., Römmert, A.K., Dammann, U., Aust, H.J. and Strack, D. (1999) The Endophyte-Host Interaction: A Balanced Antagonism? Mycological Research, 103, 1275-1283. https://doi.org/10.1017/S0953756299008540

[27] Rodriguez, R.J., White, J.F., Arnold, A.E. and Redman, R.S. (2009) Fungal Endophytes: Diversity and Functional Roles. New Phytologist, 182, 314-330. https://doi.org/10.1111/j.1469-8137.2009.02773.x

[28] Kaul, S., Gupta, S., Ahmed, M. and Dhar, M.K. (2012) Endophytic Fungi from Medicinal Plants: A Treasure Hunt for Bioactive Metabolites. Phytochemistry Reviews, 11, 487-505. https://doi.org/10.1007/s11101-012-9260-6

[29] Jordahl, J.L., Foster, L., Schnoor, J.L. and Alvarez, P.J. (1997) Effect of Hybrid Poplar Trees on Microbial Populations Important to Hazardous Waste Bioremediation. Environmental Toxicology and Chemistry, 16, 1318-1321. https://doi.org/10.1002/etc.5620160630

[30] Shanmugam, G., Poffenberger, M. and Toro Alava, J. (2000) Tide-Dominated Estuarine Facies in the Hollin and Napo ("T" and "U") Formations (Cretaceous), Sacha Field, Oriente Basin, Ecuador. AAPG Bulletin, 84, 652-682.

[31] Dashwood, M.F. and Abbotts, I.L. (1990) Aspects of the Petroleum Geology of the Oriente Basin, Ecuador. Geological Society, London, Special Publications, 50, 89-117. https://doi.org/10.1144/GSL.SP.1990.050.01.06

[32] Canfield, R.W., Bonilla, G. and Robbins, R.K. (1982) Sacha Oil Field of Ecuadorian Oriente. AAPG Bulletin, 66, 1076-1090.

[33] Arellano, P., Tansey, K., Balzter, H. and Tellkamp, M. (2017) Plant Family-Specific Impacts of Petroleum Pollution on Biodiversity and Leaf Chlorophyll Content in the Amazon Rainforest of Ecuador. PLOS ONE, 12, e0169867. https://doi.org/10.1371/journal.pone.0169867

[34] Strobel, G.A., Dirkse, E., Sears, J. and Markworth, C. (2001) Volatile Antimicrobials from Muscodor albus, a Novel Endophytic Fungus. Microbiology, 147, 2943-2950. https://doi.org/10.1099/00221287-147-11-2943

[35] Maddela, N., Scalvenzi, L., Pérez, M., Montero, C. and Gooty, J. (2015) Efficiency of Indigenous Filamentous Fungi for Biodegradation of Petroleum Hydrocarbons in Medium and Soil: Laboratory Study from Ecuador. Bulletin of Environmental Contamination and Toxicology, 95, 385-394. https://doi.org/10.1007/s00128-015-1605-6

[36] Boonchan, S., Britz, M.L. and Stanley, G.A. (2000) Degradation and Mineralization of High-Molecular-Weight Polycyclic Aromatic Hydrocarbons by Defined Fungal-Bacterial Cocultures. Applied and Environmental Microbiology, 66, 1007-1019. https://doi.org/10.1128/AEM.66.3.1007-1019.2000

[37] Bucheli, E., Gautschi, B. and Shykoff, A. (2000) Host Specific Differentiation in the Anther Smut Fungus Microbotryum violaceum as Revealed by Microsatellites. Journal of Evolutionary Biology, 13, 188-198. https://doi.org/10.1046/j.1420-9101.2000.00160.x

[38] Camacho, F.J., Gernandt, D.S., Liston, A., Stone, J.K. and Klein, A.S. (1997) Endophytic Fungal DNA, the Source of Contamination in Spruce Needle DNA. Molecular Ecology, 6, 983-987. https://doi.org/10.1046/j.1365-294X.1997.00266.x

[39] White, T.J., Bruns, T., Lee, S. and Taylor, J.W. (1990) Amplification and Direct Sequencing of Fungal Ribosomal RNA Gene for Phylogenetics. In: Innis, M.A., Gelfand, D.H., Sninsky, J.J. and White, T.J., Eds., PCR Protocols. A Guide to Methods 
and Applications, Acadamic Press, New York, 315-322.

[40] Bascom-Slack, C., Arnold, A. and Strobel, S. (2012) Student-Directed Discovery of the Microbiome and Its Products. Science, 338, 485-486.

https://doi.org/10.1126/science.1215227

[41] Edgar, R.C. (2004) MUSCLE: Multiple Sequence Alignment with High Accuracy and High Throughput. Nucleic Acids Research, 32, 1792-1797. https://doi.org/10.1093/nar/gkh340

[42] Stamatakis, A. (2006) RAxML-VI-HPC: Maximum Likelihood-Based Phylogenetic Analyses with Thousands of Taxa and Mixed Models. Bioinformatics, 22, 2688-2690. https://doi.org/10.1093/bioinformatics/btl446

[43] Gladden, J.M., Allgaier, M., Miller, C.S., Hazen, T.C., VanderGheynst, J.S., Hugenholtz, P., Simmons, B.A. and Singer, S.W. (2011) Glycoside Hydrolase Activities of Thermophilic Bacterial Consortia Adapted to Switchgrass. Applied and Environmental Microbiology, 77, 5804-5812. https://doi.org/10.1128/AEM.00032-11

[44] Lundberg, D.S., Lebeis, S.L., Paredes, S.H., Yourstone, C., Gehring, J., Malfatti, S., Tremblay, J., Engelbrektson, A., Kunin, V., del Rio, T.G., Edgar, R.C., Eickhorst, T., Ley, R.E., Hugenholtz, P., Tringe, S.G. and Dangl, J.F. (2012) Defining the Core Arabidopsis thaliana Root Microbiome. Nature, 488, 86-90. https://doi.org/10.1038/nature11237

[45] Deng, Z. and Cao, L. (2017) Fungal Endophytes and Their Interactions with Plants in Phytoremediation: A Review. Chemosphere, 168, 1100-1106.

https://doi.org/10.1016/j.chemosphere.2016.10.097

[46] Hutchins, S.R., Sewell, G.W., Kovacs, D.A. and Smith, G.A. (1991) Biodegradation of Aromatic Hydrocarbons by Aquifer Microorganisms under Denitrifying Conditions. Environmental Science \& Technology, 25, 68-76. https://doi.org/10.1021/es00013a005

[47] Beller, H.R., Grbić-Galić, D. and Reinhard, M. (1992) Microbial Degradation of Toluene under Sulfate-Reducing Conditions and the Influence of Iron on the Process. Applied and Environmental Microbiology, 58, 786-793.

[48] Hanson, K.G., Desai, J.D. and Desai, A.J. (1993) A rapid and Simple Screening Technique for Potential Crude Oil Degrading Microorganisms. Biotechnology Techniques, 7, 745-748. https://doi.org/10.1007/BF00152624

[49] Peng, A., Liu, J., Gao, Y. and Chen, Z. (2013) Distribution of Endophytic Bacteria in Alopecurus aequalis Sobol and Oxalis corniculata L. from Soils Contaminated by Polycyclic Aromatic Hydrocarbons. PLoS ONE, 8, e83054. https://doi.org/10.1371/journal.pone.0083054

[50] Baoune, H., El Hadj-Khelil, A.O., Pucci, G., Sineli, P., Loucif, L. and Polti, M.A. (2018) Petroleum Degradation by Endophytic Streptomyces spp. Isolated from Plants Grown in Contaminated Soil of Southern Algeria. Ecotoxicology and Environmental Safety, 147, 602-609. https://doi.org/10.1016/j.ecoenv.2017.09.013

[51] Lumactud, R. and Fulthorpe, R.R. (2018) Endophytic Bacterial Community Structure and Function of Herbaceous Plants from Petroleum Hydrocarbon Contaminated and Non-Contaminated Sites. Frontiers in Microbiology, 9, 1926. https://doi.org/10.3389/fmicb.2018.01926

[52] Rundell, S.M., Spakowicz, D.J., Narváez-Trujillo, A. and Strobel, S.A. (2015) The Biological Diversity and Production of Volatile Organic Compounds by Stem-Inhabiting Endophytic Fungi of Ecuador. Journal of Fungi, 1, 384-396.

https://doi.org/10.3390/jof1030384 
[53] Tian, L.S., Dai, C.C., Zhao, Y.T., Zhao, M., Yong, Y.H. and Wang, X.X. (2007) The Degradation of Phenanthrene by Endophytic Fungi Phomopsis sp. Single and Co-Cultured with Rice. China Environmental Science-Chinese Edition, 27, 757.

[54] Chen, Y., Peng, Y., Dai, C.C. and Ju, Q. (2011) Biodegradation of 4-Hydroxybenzoic Acid by Phomopsis liquidambari. Applied Soil Ecology, 51, 102-110. https://doi.org/10.1016/j.apsoil.2011.09.004

[55] Chang, S.C., Chen, M.K., Wei, D.L. and Cheng, M.K. (2007) Isolation and Characterization of a Polycyclic Aromatic Hydrocarbons-Degrading Enzyme from Xylaria regalis. Fungal Science, 22, 25-33.

[56] Balaji, V. and Ebenezer, P. (2008) Optimization of Extracellular Lipase Production in Colletotrichum gloeosporioides by Solid State Fermentation. Indian Journal of Science and Technology, 1, 1-8.

[57] Bezalel, L., Hadar, Y. and Cerniglia, C.E. (1997) Enzymatic Mechanisms Involved in Phenanthrene Degradation by the White Rot Fungus Pleurotus ostreatus. Applied and Environmental Microbiology, 63, 2495-2501.

[58] Balaji, V., Arulazhagan, P. and Ebenezer, P. (2014) Enzymatic Bioremediation of Polyaromatic Hydrocarbons by Fungal Consortia Enriched from Petroleum Contaminated Soil and Oil Seeds. Journal of Environmental Biology, 35, 521-529.

[59] Takahashi-Ando, N., Ohsato, S., Shibata, T., Hamamoto, H., Yamaguchi, I. and Kimura, M. (2004) Metabolism of Zearalenone by Genetically Modified Organisms Expressing the Detoxification Gene from Clonostachys rosea. Applied and Environmental Microbiology, 70, 3239-3245. https://doi.org/10.1128/AEM.70.6.3239-3245.2004

[60] Sack, U., Heinze, T.M., Deck, J., Cerniglia, C.E., Cazau, M.C. and Fritsche, W. (1997) Novel Metabolites in Phenanthrene and Pyrene Transformation by Aspergillus niger. Applied and Environmental Microbiology, 63, 2906-2909.

[61] Giraud, F., Guiraud, P., Kadri, M., Blake, G. and Steiman, R. (2001) Biodegradation of Anthracene and Fluoranthene by Fungi Isolated from an Experimental Constructed Wetland for Wastewater Treatment. Water Research, 35, 4126-4136. https://doi.org/10.1016/S0043-1354(01)00137-3

[62] Cerniglia, C.E. and Sutherland, J.B. (2010) Degradation of Polycyclic Aromatic Hydrocarbons by Fungi. In: Timmis, K.N., Ed., Handbook of Hydrocarbon and Lipid Microbiology, Springer, Berlin, Heidelberg, 2079-2110. https://doi.org/10.1007/978-3-540-77587-4_151

[63] Alberto, R.N., Costa, A.T., Polonio, J.C., Santos, M.S., Rhoden, S.A., Azevedo, J.L. and Pamphile, J.A. (2016) Extracellular Enzymatic Profiles and Taxonomic Identification of Endophytic Fungi Isolated from Four Plant Species. Genetics and Molecular Research: GMR, 15, 1-12.

[64] Korda, A., Santas, P., Tenente, A. and Santas, R. (1997) Petroleum Hydrocarbon Bioremediation: Sampling and Analytical Techniques, in Situ Treatments and Commercial Microorganisms Currently Used. Applied Microbiology and Biotechnology, 48, 677-686. https://doi.org/10.1007/s002530051115

[65] Umanu, G. and Dodo, D.S. (2013) Assessment of Oil-Eating Fungi Isolated from Spent Engine Oil Polluted Soil Environments. The Pacific Journal Science and Technology, 14, 609-616.

[66] Adams, G.O., Fufeyin, P.T., Okoro, S.E. and Ehinomen, I. (2015) Bioremediation, Biostimulation and Bioaugmention: A Review. International Journal of Environmental Bioremediation \& Biodegradation, 3, 28-39.

[67] Hidayat, A. and Tachibana, S. (2013) Crude Oil and n-Octadecane Degradation 
Under Saline Conditions by Fusarium sp., F092. Journal of Environmental Science and Technology, 6, 29-40.

[68] Ding, J., Cong, J., Zhou, J. and Gao, S. (2008) Polycyclic Aromatic Hydrocarbon Biodegradation and Extracellular Enzyme Secretion in Agitated and Stationary Cultures of Phanerochaete chrysosporium. Journal of Environmental Sciences, 20, 88-93. https://doi.org/10.1016/S1001-0742(08)60013-3

[69] Wang, S., Nomura, N., Nakajima, T. and Uchiyama, H. (2012) Case Study of the Relationship between Fungi and Bacteria Associated with High-Molecular-Weight Polycyclic Aromatic Hydrocarbon Degradation. Journal of Bioscience and Bioengineering, 113, 624-630. https://doi.org/10.1016/j.jbiosc.2012.01.005

[70] Rahman, K.S.M., Rahman, T.J., Kourkoutas, Y., Petsas, I., Marchant, R. and Banat, I.M. (2003) Enhanced Bioremediation of $n$-Alkane in Petroleum Sludge Using Bacterial Consortium Amended with Rhamnolipid and Micronutrients. Bioresource Technology, 90, 159-168. https://doi.org/10.1016/S0960-8524(03)00114-7

[71] Leahy, J.G. and Colwell, R.R. (1990) Microbial Degradation of Hydrocarbons in the Environment. Microbiological Reviews, 54, 305-315. 